\title{
Estimates of cancer risk from chloroform exposure during showering in Taiwan
}

\author{
H.-W. Kuo ${ }^{\text {a,* }}$, T.-F. Chiang ${ }^{\text {a }}$, I.-I. Lo ${ }^{\text {a }}$, J.-S. Lai ${ }^{\text {a }}$, C.-C. Chan ${ }^{\text {b }}$, J.-D. Wang ${ }^{\text {b }}$ \\ ${ }^{a}$ Institute of Environmental Health, China Medical College, No. 91, Hsueh-Shin Road, Taichung, Taiwan \\ ${ }^{\mathrm{b}}$ Institute of Occupational Medicine and Industrial Hygiene, College of Public Health, National Taiwan University, \\ Taipei, Taiwan
}

Received 14 December 1997; accepted 2 February 1998

\begin{abstract}
The purpose of this study was to compare the cancer risk with chloroform exposure during showering. The study concentrated on the three major metropolitan areas of Taiwan. Total exposure was measured based on a combination of ingestion, inhalation and skin absorption. A total of 137 tap water samples were taken from 26 locations within the Taipei (north), Taichung (central) and Kaohsiung (south) areas. Analysis of VOC compounds was performed according to the US EPA Method 524. Chloroform concentrations were highest in Kaohsiung (60.19 $\mu \mathrm{g} / \mathrm{l})$, followed by Taipei $(18.83 \mu \mathrm{g} / \mathrm{l})$ and Taichung $(17.55 \mu \mathrm{g} / \mathrm{l})$. Based on the two-resistance theory to volatilization in showers, when air flow rate is increased, chloroform concentrations in the air significantly decrease. A 10-min shower would result in chloroform exposure with a 3:4:3 ratio (ingestion, inhalation, skin absorption). However, that changes to 1:7:2 for a 20-min shower under the same conditions. The cancer risk was highest in Kaohsiung at 17.59 per million for a 10 -min shower and 64.77 per million for a 20 -min shower. The lowest cancer risk was found in Taichung at 4.99 and 11.50 per million for a 10- and 20-min shower, respectively. Although ingestion is commonly considered to be the primary source of exposure to chloroform from tap water, inhalation and skin absorption exposure concentrations were found to be even higher. (c) 1998 Elsevier Science B.V. All rights reserved.
\end{abstract}

Keywords: Chloroform; Cancer risk; Showering

\section{Introduction}

Tap water in Taiwan has been chlorinated for approx. 30 years. This has caused the production of relatively small amounts of chloroform and

\footnotetext{
* Corresponding author. Tel.: +886 4 054076; fax: +886 4 2019901; e-mail: wukuo@cmce.cmcedu.tw
}

other disinfectant by-products (DBP), such as haloacetic acids (HAAs), haloacetonitriles (HANs), chloropicrin (CPK), chlorohydrate (CH) and other disinfectant by-products (Chiang, 1995). Due to poor water quality from rivers and underground sources, the Taiwan Water Supply Company (Taiwan Water Supply Corp., 1995) has added extra amounts of chlorine during treatment, with concentrations at their peak during 
summer. Consequently, disinfectant by-products are being produced in dangerously high amounts. Morris et al. (1992) used meta-analysis to find a positive association between consumption of chlorination by-products in drinking water and bladder and rectal cancer in humans. In a 1995 study on trihalomethanes in drinking water and tumors in animals, Attias et al. (1995) estimated a carcinogenic risk for different THM combinations which vary from $2.7 \times 10^{-7}$ to $4.6 \times 10^{-6}$ per $\mu / 1$. Results from studies (Aschengram et al., 1993; Bove et al., 1995) involving congenital anomalies, stillbirths, and neonatal deaths in relation to quality of drinking water were not statistically stable. Although traditional risk assessments for water often only considered exposure from ingestion, in order to accurately measure total exposure to THMs inhalation and dermal absorption need to be included as well. It has been shown that showering increases body burden due to inhalation, exposure and dermal absorption (Weisel and Jo, 1996). Little (1992) applied the two-resistance theory to contaminant volatilization in showers and found several factors can affect volatility including: the contaminant's concentration in water and its physical and chemical characteristics, volume of water and air exchange rate in the shower, water flow rate, water temperature, etc. Measuring these factors as well as others provides a more accurate assessment of variations in contaminant volatility. The tworesistance theory is applied in the current study to estimate total chloroform exposure and calculate the cancer risk for a comparison of the three major metropolitan areas in Taiwan. These results can then be used by the government as a reference for regulation purposes.

\section{Materials and methods}

\subsection{Study areas}

The study areas which included the cities of Taipei, Taichung and Kaohsiung contain onequarter of the total Taiwanese population. Due to the overall poor water quality throughout the island, tap water is not directly consumed so 'drinking water' is defined for purposes of this study as tap water that has been boiled. A total of 137 samples of tap water and 68 samples of drinking water were taken from the three study sites.

\subsection{Methods}

Twenty-four purgable VOCs were analyzed using modified US EPA Method 524. Details regarding quality control and procedures can be found in published studies by Kuo et al. (1996) and by Kuo et al. (1997). Total exposure to chloroform is divided into three major routes: ingestion, inhalation, and dermal absorption. Parameters are based on those reported by Little (1992) and by Beavers et al. (1996). Ingestion was assumed to be $2 \mathrm{l}$ /person per day. One person was estimated to have a body weight of $70 \mathrm{~kg}$ and an expected life span of 75 years. Inhalation concentrations were found to be based on the following estimates: volume of air in the shower $\left(V_{\mathrm{s}}\right)$ was $1.2 \mathrm{~m}^{3}$, volumetric water flow rate $\left(Q_{\mathrm{L}}\right)$ was $5 \mathrm{l} / \mathrm{min}$, volumetric flow rate $\left(Q_{\mathrm{G}}\right)$ was 50 $1 / \mathrm{min}$, air exchange rate $(\mathrm{ACH})$ was 2.5 times $/ \mathrm{h}$, water temperature $\left(T_{\mathrm{w}}\right)$ was $44^{\circ} \mathrm{C}$, height of shower head was $1.8 \mathrm{~m}$ and overall mass transfer coefficient with a liquid phase basis $\left(K_{\mathrm{OLA}}\right)$ was $7.4 \mathrm{l} /$ time. The temperature correction coefficient for Henry's law constant $(J)$ was 0.1312 (dimensionless). Estimated concentration of chloroform in the air $\left(Y_{\mathrm{s}}\right)$ was:

$Y_{\mathrm{s}}=a / b+(-a / b) \exp ^{(-b t)}$

$a=\left\{Q_{\mathrm{L}} C_{\mathrm{w}}\left(1-\exp ^{(-N)}\right)\right\} / V_{\mathrm{S}}$

$b=\left\{\left(Q_{\mathrm{L}} / \mathrm{m}\right)\left(1-\exp ^{(-N)}\right)+Q_{\mathrm{G}}\right\} / V_{\mathrm{S}}$

$N=\left(K_{O L A}\right) / Q_{\mathrm{L}}$

Inhalation concentration was estimated to be $\left\{\left(Y_{\mathrm{si}}\right.\right.$ $\left.\left.+Y_{\mathrm{s}}\right) / 2\right\} \times T(\min ) \times 20\left(\mathrm{~m}^{3} /\right.$ day $) \times 50 \%$. The $Y_{\mathrm{si}}$ (initial concentration in the shower air at $t=0$ ) of chloroform was assumed to be 0 . The volume of air inhalation was assumed to be $20 \mathrm{~m}^{3} /$ day. The absorption efficiency in alveoli was assumed to be $59 \%$. The shower time $=T$.

Dermal absorption was based on the assumption of the total surface area of skin $=18000 \mathrm{~cm}^{2}$ and water was estimated to contact $80 \%$ of the 
total surface area of skin. The permeation constant of the skin was assumed to be $0.2 \mathrm{~cm} / \mathrm{h}$. The chloroform concentration in the water was $C_{\mathrm{w}}$. The skin absorption concentration was estimated to be $T(\mathrm{~min}) \times 0.2(\mathrm{~cm} / \mathrm{h}) \times 18000\left(\mathrm{~cm}^{2}\right)$ $\times 80 \% \times C_{\mathrm{w}}$. The equation (risk estimation of chloroform $=$ chloroform exposure $\times$ slope factor) was used to find the number of persons who may acquire cancer during one's life span due to chloroform exposure from ingestion, inhalation, and dermal absorption based on a population of 1 million (Bull, 1990).

\section{Results and discussion}

Drinking and tap water from the three major metropolitan areas of Taiwan were measured for THMs, 1,2-dichloroethane and benzene. Results are shown in Table 1. Based on measurements from tap water, the cancer risk was highest in Kaohsiung (376.70), followed by Taipei (220.73) and Taichung (161.77). However, according to drinking water measurements Taipei was highest (106.63), then Kaohsiung (87.69) and Taichung (63.10). Although chloroform was found in highest concentrations in tap and drinking water among all THMs, its carcinogenic potential was lowest. The cancer risk was highest for bromodochloromethane and dibromochloromethane. Because benzene and bromoform were found in the lowest concentrations in tap and drinking water, their respective cancer risks were insignificant.

According to a Taiwan Department of Health report (Taiwan Department of Health, 1996), an island-wide comparison of mortality due to cancer was highest in the southern region including Kaohsiung city and county. The most common forms were lung, liver, bladder, and skin cancer. Two possible factors for the high cancer mortality in the southern region are due to its vicinity to Taiwan's petrochemical industry and the poor quality of its underground and tap water. The current study found a significant correlation between standardized mortality ratio (SMR) of bladder cancer among males and THM concentrations in tap water $(r=0.48, P<0.01)$. Morris et al. (1992) used meta-analysis to find a significant relationship between bladder and rectal can-
Table 1

Estimates of cancer risk from tap and drinking water from the three metropolitan areas

\begin{tabular}{|c|c|c|c|}
\hline \multirow[t]{2}{*}{ VOCS } & \multirow[t]{2}{*}{ Area } & \multicolumn{2}{|c|}{ Cancer risk $\left(10^{-6}\right)$} \\
\hline & & Tap water & Drinking water \\
\hline \multirow[t]{3}{*}{ THMS } & Taichung & 131.69 & 20.34 \\
\hline & Taipei & 197.73 & 83.41 \\
\hline & Kaohsiung & 301.32 & 49.32 \\
\hline \multirow{3}{*}{$\mathrm{CHCl}_{3}$} & Taichung & 5.97 & 1.310 \\
\hline & Taipei & 6.40 & 2.40 \\
\hline & Kaohsiung & 23.52 & 4.89 \\
\hline \multirow[t]{3}{*}{$\mathrm{CH}_{2} \mathrm{Cl}_{2} \mathrm{Br}_{2}$} & Taichung & 101.90 & 14.89 \\
\hline & Taipei & 144.08 & 66.08 \\
\hline & Kaohsiung & 219.78 & 36.19 \\
\hline \multirow[t]{3}{*}{$\mathrm{CH}_{2} \mathrm{ClBr}_{2}$} & Taichung & 23.58 & 4.16 \\
\hline & Taipei & 47.45 & 14.93 \\
\hline & Kaohsiung & 58.02 & 8.24 \\
\hline \multirow[t]{3}{*}{$\mathrm{CHBr}_{3}$} & Taichung & 0.24 & NA \\
\hline & Taipei & NA & NA \\
\hline & Kaohsiung & NA & NA \\
\hline \multirow[t]{3}{*}{$\mathrm{C}_{2} \mathrm{H}_{2} \mathrm{Cl}_{2}$} & Taichung & 29.90 & 42.34 \\
\hline & Taipei & 22.74 & 22.96 \\
\hline & Kaohsiung & 75.38 & 37.97 \\
\hline \multirow[t]{3}{*}{$\mathrm{C}_{6} \mathrm{H}_{6}$} & Taichung & 0.18 & 0.42 \\
\hline & Taipei & 0.06 & 0.26 \\
\hline & Kaohsiung & ND & 0.40 \\
\hline \multirow[t]{3}{*}{ Total risk } & Taichung & 161.77 & 63.10 \\
\hline & Taipei & 220.73 & 106.63 \\
\hline & Kaohsiung & 376.70 & 87.69 \\
\hline
\end{tabular}

cer and THM concentrations in drinking water. In studies concerning THM ingestion published in 1988 and 1981, Zierler and Danley (1988) and Wilkins and Comstock (1981) found that when chloroamide was added to the water supply, there was a significant increase in the incidence of and mortality due to bladder cancer. However, in a 1995-study in Italy by Attias et al. (1995) no correlation was found between THM concentrations in drinking water and the incidence of bladder cancer. Because numerous factors lead to the incidence of cancer, it is difficult to find a clear correlation between ingestion of THMs and cancer and to accurately measure the body's total exposure to THMs. Mathematical models based on animal and epidemiological data analyses can be used to calculate cancer risk from THMs concentration in drinking water which can then be used by the government for regulation purposes. 
Using air flow rates of 0,50 and $150\left(1^{3} / \mathrm{min}\right)$ chloroform concentrations in the air were estimated during 10- and 20-min showers. Results are displayed in Table 2. Chloroform concentrations increased when shower time increased and decreased when air flow rate increased. Based on a 10 -min shower in Kaohsiung with a 60.19 chloroform concentration in water and 0 air flow, 1.34 $\mu \mathrm{g} / 1$ of chloroform was produced in the air. When air flow was increased to $50 \mathrm{l}^{3} / \mathrm{min}$, the chloroform produced decreased to $1.10 \mu \mathrm{g} / 1$ $(18.0 \%)$. At $150 \mathrm{l}^{3} / \mathrm{min}$, chloroform decreased to $0.78 \mu / 1(42 \%)$ from the original 0 air flow rate. Based on a 20 -min shower with 0 air flow rate, the chloroform concentration in air was $2.45 \mu \mathrm{g} / 1$. With an air flow of $50 \mathrm{l}^{3} / \mathrm{min}$, the chloroform concentration in air decreased to $1.71 \mu \mathrm{g} / \mathrm{l}$ $(30.2 \%)$. At $150 \mathrm{l}^{3} / \mathrm{min}$, the concentration decreased to $0.96 \mu \mathrm{g} / \mathrm{l}(60.8 \%)$ from the original 0 air flow rate. In addition to air flow rate, many factors affect chloroform concentrations in the air which are difficult to control, such as water flow rate, volume of air in shower, water temperature, height and diameter of shower head, and chloroform concentration in the water. Although increasing air flow rate is possibly the easiest and most effective way to decrease chloroform concentrations in the air, the general population in Taiwan overlooks or is unaware of this fact. Due to the relatively small volume of shower space in Taiwan, chloroform concentrations in the air can be exceptionally high. Pellizzari et al. (1986) reported that concentrations of certain VOCs present in indoor air have been found to be more than 10 times higher than outdoors. One potential source of VOCs in the air is the transfer from contaminated tap water during residential water use in showers, dishwashers, and washing machines. According to a 1993-study by Wallace et al. (1993), the possibility of chloroform inhalation increased significantly when dishwashers and washing machines were in operation.

The two-resistance theory was applied to calculate total exposure of chloroform due to skin absorption and inhalation during showering. Table 3 shows a comparison of the three study sites based on total exposure (ingestion, inhalation and skin absorption) and the cancer risk after 10- and 20-min showers. Results showed total exposure and cancer risk increased with shower time. The exposure ratio was 3:4:3 for a 10-min shower and 1:7:2 for a 20 -min shower. As shower time increased, exposure from inhalation and skin absorption increased significantly when water contained high concentrations of chloroform. Because chloroform concentrations in the water are highest in Kaohsiung, increasing shower time from 10 to $20 \mathrm{~min}$, cancer risk can increase four times (from 17.59 to 64.77 ) compared to only twice in Taipei (from 6.42 to 13.27 ).

These results are consistent with those found by Andelman (1985a,b) who used a one-compart-

Table 2

Estimate of chloroform concentrations in the air during showering based on different air flow rates

\begin{tabular}{lllrr}
\hline $\begin{array}{l}\text { Air flow rate } \\
\left(1^{3} / \mathrm{min}\right)\end{array}$ & Area & Chloroform conc. & \multicolumn{2}{c}{ Chloroform conc. in air $\left(\mathrm{mg} / \mathrm{m}^{3}\right)$} \\
\cline { 2 - 4 } & & in water $(\mu \mathrm{g} / \mathrm{l})$ & 7.2 \\
\hline 0 & Taichung & 17.55 & 3.9 & 7.7 \\
& Taipei & 18.83 & 4.2 & 24.5 \\
& Kaohsiung & 60.19 & 13.4 & 6.9 \\
50 & Taichung & 17.55 & 3.2 & 5.3 \\
& Taipei & 18.83 & 3.4 & 17.1 \\
& Kaohsiung & 60.19 & 2.3 & 2.8 \\
& Taichung & 17.55 & 2.4 & 3.0 \\
& Taipei & 18.83 & 7.8 & 9.6 \\
\hline
\end{tabular}


Table 3

Total exposure $(\mu \mathrm{g})$ and cancer risk $\left(10^{-6}\right)$ from chloroform exposure during showering in the three metropolitan areas

\begin{tabular}{|c|c|c|c|c|}
\hline & Taichung & Taipei & Kaohsiung & $\%$ of total exposure \\
\hline $\begin{array}{l}\text { Chloroform conc. in } \\
\text { water }(\mu \mathrm{g} / 1)\end{array}$ & 17.55 & 18.83 & 60.19 & \\
\hline \multicolumn{5}{|l|}{ Shower time: $10-\min$} \\
\hline Ingestion & 7.72 & 14.14 & 28.76 & 30 \\
\hline Inhalation & 13.19 & 14.58 & 45.83 & 43 \\
\hline Skin absorption & 8.42 & 9.04 & 28.89 & 27 \\
\hline Total dose & 29.83 & 37.76 & 103.48 & \\
\hline Cancer risk & 4.99 & 6.42 & 17.59 & \\
\hline \multicolumn{5}{|l|}{ Shower time: $20-\mathrm{min}$} \\
\hline Ingestion & 7.72 & 14.14 & 28.76 & 12 \\
\hline Inhalation & 43.06 & 45.83 & 294.44 & 67 \\
\hline Skin absorption & 16.85 & 18.08 & 57.78 & 21 \\
\hline Total dose & 67.63 & 78.05 & 380.98 & \\
\hline Cancer risk & 11.50 & 13.27 & 64.77 & \\
\hline
\end{tabular}

ment indoor air quality model to estimate that the uptake of VOCs inhaled was six times greater than that ingested. Beavers et al. (1996) estimated inhalation and ingestion of benzene and three other aromatic hydrocarbons typically found in gasoline-contaminated water. Results showed the ratio was 3:4:3 (ingestion/inhalation/skin absorption) and shower-related and non-shower-related exposure to benzene was $55-45 \%$. Volatilization of chemicals from indoor water uses is of growing concern, particularly as water supplies become increasingly contaminated. Exposure ratios can vary due to differences in assumptions and parameters used in mathematical models. Maxwell et al. (1991) concluded that the ratio of the lifetime inhalation to ingestion doses is probably in the range of $0.6-1.5$ (and may be as high as 5.7) and the ratio of the lifetime dermal to ingestion doses is probably 0.3 but may be as high as 1.8. Jo et al. (1990) quantified the relationship between chloroform concentrations in shower water, shower air, and exhaled breath of individuals exposed while showering. Data showed that the chloroform increase in shower air and breath concentrations increased with chloroform concentrations in water. Chinery and Gleason (1993) used shower and PB-PK (physiologically based pharmacokinetic) models to predict breath concentration and the absorbed dose of chloroform after exposure while showering. They estimated that the ratio of dermally to inhaled absorbed doses ranged from 0.6 to 2.2 and the expected value was 0.75 . They suggested a reasonable value of skin permeability coefficient for chloroform used in the simple steady-state model would be $0.2 \mathrm{~cm} / \mathrm{h}$.

In a 1983-study, Mackay and Yeun (1983) noted that the rate of the volatilization of a chemical form is dependent on its molecular-diffusivity properties. A two-resistance model is used to describe the process in which the volatilizing chemical has to first diffuse across a liquid film at the air-water interface, followed by diffusion across the air film. The water-air interfacial areas and temperature of the water uses are critical determining factors in the rate of mass transfer. Other indoor water uses involve different quantities and flows of water, residence times in the water appliances, degrees of mixing and turbulence and temperatures. So, the extents of volatilization among the water uses, even for a given chemical, should vary. Alveolar breathing sampling can be used to verify the post-shower breath data, help assess the importance of dif- 
ferent routes of exposure (e.g. proportion of dermal vs. inhalation routes), establish uptake and eliminate kinetics. Lindstrom and Pleil (1996) used alveolar breathing measurements to calculate blood-contaminate concentrations and compartment-specific half-lives, confirm minimum absorbed dose and characterize significant shortterm exposure phenomenon. Even though most parameters followed were established in previous studies, our findings are reliable and can be used by the government to regulate VOC concentrations in the water and to inform the public about certain safety measures that can minimize exposure to VOCs. Future studies using the two-resistance theory should establish parameters uniquely suited for Taiwan in order to make accurate cancer risk assessments due to VOC exposure.

\section{Conclusion}

In Taiwan, standards are set for ingestion of water but not for other routes of exposure, such as inhalation and dermal absorption. This is the first study to estimate the cancer risk from exposure to VOCs in Taiwan and the chloroform exposure during showering. Cancer risk results showed Kaohsiung was highest for tap water (376.70) and Taipei for drinking water (106.63). Based on the two-resistance theory, a 10-min shower resulted in chloroform exposure with a 3:4:3 ratio (ingestion, inhalation and skin absorption) and 1:7:2 for a 20-min shower. As shower time increased, exposure due to inhalation increased significantly. Yet, as air flow rate increased concentrations of chloroform decreased. Because the government does not actively promote efforts to decrease chloroform in tap water, the general population must make efforts to decrease personal exposure, such as increasing air flow and decreasing the duration of shower time.

\section{Acknowledgements}

This study was supported by a special grant from National Science Council NSC 85-2621-p039-001-Z.

\section{References}

Andelman JB. Human exposure to volatile halogenated organic chemical in indoor and outdoor air. Environ Health Perspect 1985a;62:313-318.

Andelman JB. Inhalation exposure in the home to volatile organic contaminants of drinking water. Sci Total Environ 1985b;47:443-460.

Aschengram A, Zierier S, Cohen A. Quality of community drinking water and outcome of late adverse pregnancy outcome. Arch Environ Health 1993;48:105-113.

Attias L, Contu A, Loizzo A, Massiglia M, Valente P, Zapponi GA. Trihalomethanes in drinking water and cancer: a risk assessment and integrated evaluation of available data, in animals and humans. Sci Total Environ 1995;171:61-68.

Beavers JD, Himmelstein JS, Hammond SK, Smith TJ, Kenyon EM, Sweat CP. Exposure in household using gasoline-contaminated water. J Occup Environ Med 1996; 38:35-38.

Bove F, Fulcomer MC, Sarrin JE. Public drinking water contamination and birth outcome. Am J Epidemiol 1995; 141:850-862.

Bull RJ. Evaluation of health risk association with disinfection. Crit Rev Environ Control 1990;20:77-113.

Chiang TG. By-product of drinking water and treatment techniques in Taiwan area. Taiwan EPA, EPA84-E3J1-0901, 1995.

Chinery RL, Gleason AK. A compartmental model for the prediction of breath concentration and absorbed dose of chloroform after exposure while showering. Risk Anal 1993;13:51-63.

Jo WK, Wiesel CP, Lioy PJ. Routes of chloroform exposure and body burden from showering with chlorinated tap water. Risk Anal 1990;10:575-580.

Kuo HW, Lo II, Chan CC, Lai JS, Wang JD. Volatile organic compounds in water near petrochemical factories in Taiwan. Chemosphere 1996;33:913-920.

Kuo HN, Chiang TF, Lo II, Lai JS, Chan CC, Wang JD. VOC concentration in Taiwan's household drinking water. Sci Total Environ 1997;208:41-47.

Lindstrom AB, Pleil JD. A methodological approach for exposure assessment studies in residences using volatile organic compound-contaminated water. J Air Waste Manage Assoc 1996;46:1058-1066.

Little JC. Applying the two-resistance to contaminant volatilization in shower. Environ Sci Technol 1992;26: 1341-1349.

Mackay D, Yeun ATK. Mass transfer coefficient correlations for volatilization of organic solutes from water. Environ Sci Technol 1983;17:211-217.

Maxwell NI, Barmaster DE, Ozonoff D. Trihalomethanes and maximum contaminant levels: the significance of inhalation and dermal exposure to chloroform in household water. Regul Toxicol Pharmacol 1991;14:297-312.

Morris RD, Audet AM, Angelillo IF, Chalmers TC, Mosteller F. Chlorination, chlorination by products and cancer. Am J Public Health 1992;82:955-963. 
Pellizzari ED, Michael LC, Perritt RL, Smith D, Hartwell TD, Sebestik J. Comparison of indoor and outdoor toxic air pollutant levels in several Southern California communities. Final Report on Contract EPA 68-02-4544, US Environmental Protection Agency, Washington, DC, 1986.

Taiwan Department of Health. Cancer registry annual report. Taiwan, ROC, 1996:12-15.

Taiwan Water Supply Corp. The statistical data and water quality. Taiwan, ROC, 1995.

Wallace L, Pellizzari ED, Goldon S. A liner model relating breath concentrations to environmental exposure: applica- tion to a chamber study. J Expos Anal Environ Epidemiol 1993;3:75-102.

Weisel CP, Jo WK. Ingestion, inhalation, and dermal exposure to chloroform and trichloroethane from tap water. Environ Health Perspect 1996;104:48-51.

Wilkins JR, Jr, Comstock GW. Source of drinking water at home and site-specific cancer incidence in Washing county, Maryland. Am J Epidemiol 1981;114:178-190.

Zierler S, Danley RA. Bladder cancer in Massachusetts related to chlorinated and chloroaminated drinking water. A case-control study. Arch Environ Health 1988;43:195-200. 